\title{
LITERATURA E FORMAÇÃO EM ADORNO
}

Filipe Ceppas

RESUMO

O presente texto apresenta temas conjugados da teorização de Adorno sobre literatura e formação. Ele chama a atenção para 'aspectos pós-modernos' desses temas e indica sua importância para superar os limites de uma leitura lamurienta das ideias de Adorno.

PALAVRAS-CHAVE: Adorno; Literatura; Pós-modernismo.

$\mathrm{P}$ ara muitos, a palavra "literatura" desperta uma representação mais ou menos bem delimitada, reunindo obras de ficção, crônicas, poesia e dramaturgia. Essa delimitação reside, via de regra, numa separação entre uma escrita voltada sobretudo para o prazer, ou lazer, e todas as outras, o que, na verdade, deixa de lado a especificidade e a complexidade da literatura enquanto conjunto bastante díspar de tradiçôes orais e escritas, e o fato de que "prazer" e "lazer" não são conceitos assim tão evidentes. Levando isso em conta, a primeira questão referente à relação entre literatura e formação — ou aquela parte da formação que é devida à escola, enquanto instituição que deveria garantir uma base cultural comum, laica e republicana, a todas as crianças de uma nação - é a dos riscos inerentes à "escolarização", no sentido de absolutizar a literatura como mero ornamento cultural e produto ahistórico. Como tal, ela habitaria a escola a contragosto, uma vez que o ensino e a aprendizagem escolares são tidos como da ordem do esforço, do trabalho, do desprazer, contrariamente à origem etimológica da palavra e à instituição ela mesma, voltada para aqueles que, na Grécia clássica, podiam se dedicar ao "ócio", que não estavam forçados a ganhar a vida com o suor de seu rosto, mas tinham um compromisso inequívoco com a organização e os destinos da pólis. Com essa questão inicial, ainda um pouco esquemática, identificamos temas caros a Adorno, trabalhados em sua obra, e de forma mais sucinta em textos como "É a arte alegre?" e "Tempo Livre". 
Uma outra questão importante acerca das relações entre literatura e formação diz respeito à linguagem, ou àquilo que, nas modulações de expressão de uma língua, põe em conflito formas de ver o mundo, padrôes e tradiçóes culturais. Nos seus textos sobre literatura, Adorno trabalhou diversas questóes referentes à linguagem, abordando a seu modo os conflitos aí implicados, a partir da análise de obras e autores fundamentais: sobretudo problemas inerentes às relaçooes entre forma e conteúdo, assim como a inalienável remissão da literatura à sociedade em contraposição ao ideal de autonomia da arte.

Não menos importante para pensar literatura e formação em Adorno é a contraposição entre arte séria e cultura de massa. Mas talvez valha a pena defender que esta não se compreende bem sem menção aos problemas acima indicados. Muitos comentários acerca da filosofia de Adorno perdem-se na eterna ruminação de um certo "pessimismo elitista", que acaba por reificar os contornos mais críticos de suas formulações, divorciando-os do complexo jogo dialético negativo. A arte é, para Adorno, o horizonte último de resistência em um mundo administrado, e ela só o é, sem dúvida, na medida em que radicalizamos nossa desconfiança perante qualquer promessa de linha de fuga. Fazê-lo implica, contudo, uma luta com a linguagem, luta filosófica e decisiva contra a reificação, o que significa não parar ali onde Adorno indicou seus problemas fundamentais.

São esses os três momentos que gostaria de apresentar aqui sob o título de literatura e formação em Adorno: indicar as tensôes inerentes à presença da literatura no contexto escolar e à ideia de formação; mostrar como algumas ideias adornianas acerca da linguagem, a partir da literatura, póem em relevo problemas centrais para pensar a formação; e seguir algumas pistas que essas duas perspectivas nos oferecem para pensar de modo renovado a oposição entre arte séria e cultura de massa.

Um texto central de Adorno para pensar a formação é "Teoria da semicultura". Nele, Adorno apresenta a formação cultural como um "campo de forças" que não pode congelar-se em categorias fixas, "sejam elas do espírito ou da natureza, de transcendência ou de acomodação": "Na hipóstase do espírito, mediante a cultura, a reflexão glorifica a separação social colocada entre o trabalho do corpo e o traballho do espírito" (ADORNO, 1996, pp. 390-391). "A filosofia e os professores" é outro texto em que Adorno concentra a discussão diretamente sobre a questão da formação, subscrevendo, não sem reservas, a 
concepção fichteana da filosofia como "autoconsciência viva do espírito", assim como sua centralidade para a concepção clássica de formação, gestada no seio do idealismo alemão. Mas o termo "espírito", em Adorno, carrega sempre sua condição corpórea irremediável de ferida e cicatriz. Ao afirmar que "cada termo filosófico é a cicatriz endurecida de um problema irresoluto" (ADORNO, 1976, p. 10), Adorno nos propóe mais do que uma mera metáfora ou, antes, nos convida a pensar na materialidade mesma das metáforas com as quais o espírito se descreve a si mesmo.

Também a literatura está marcada por uma tensão semelhante, entre o espírito e a letra, o que é exemplificado de modo mais radical pela obra de Kafka - e podemos dizer que esta tensão expressa um princípio central da estética adorniana:

Em nenhuma obra de Kafka a aura da idéia infinita desaparece no crepúsculo, em nenhuma obra se esclarece o horizonte. Cada frase é literal, e cada frase significa. Esses dois aspectos não se misturam, como exigiria o símbolo, mas se distanciam um do outro, e o ofuscante raio da fascinação surge do abismo que se abre entre ambos. (ADORNO, 1998, p. 240)

A tensão entre o espírito e a letra, entre o sentido e o literal, é uma chave interpretativa que póe em relevo alguns problemas caros a Adorno: a negação da ideia de interpretação como desvelamento de uma "mensagem", central em determinadas concepçóes simbólicas e hermenêuticas da arte; a natureza sempre problemática das relaçóes entre forma e conteúdo; e, por fim, a dimensão cognitivo-experiencial da arte bloqueada pelas condiçóes objetivas de sua produção e recepção, bloqueio que se transforma ele mesmo em tema central.

O espírito hipostasiado na sociedade marcada pela hierarquização entre trabalho material e imaterial significa, vulgarmente, a identificação da formação com a aquisição dos "valores superiores da cultura", que se encontram entretanto efetivamente divorciados daqueles fins que os faziam original e pretensamente elevados, isto é, valores que, desde Platão, deveriam ajudar a normatizar ou maximizar a excelência da conduta dos indivíduos numa realidade cindida. Neste quesito, Adorno o tempo todo ressalta que a principal potência da arte, como Platão muito bem reconheceu, é seu caráter fantasma- 
górico e político em sentido amplo: o querer o que não existe é por definição posicionar-se perante o que existe, ainda que seja com a finalidade de apenas melhor conformar-se a este. A radicalização da autoconsciência do espírito e autoconsciência da potência da arte como outro da sociedade, que corresponde à superação burguesa de formas arcaicas de organização econômica e social e, portanto, à constituição e diversificação da liberdade individual da expressão, tende a hipostasiar-se numa postura cética diante da complexidade mesma das relaçôes entre indíviduo e sociedade. Neste movimento, o "espírito elevado" acaba refém do princípio de uma mera recompensa lúdica e ilustrada diante da barbárie vigente, o que é ao mesmo tempo contraditório e coerente com o fato de que, a partir da modernidade, as "obras superiores" da cultura apenas na aparência se prestam ao papel de recompensa apaziguadora.

Este caráter antinômico da arte aparece com toda sua força na literatura moderna, em Baudelaire e Proust, cujas obras já denunciam a falência do ideal de formação. Conforme aprofunda-se esse processo de falência, "a única possibilidade de sobrevivência que resta à cultura”, nos diz Adorno, "é a reflexão crítica sobre a semiformação, em que necessariamente se converteu" (ADORNO, 1996, p. 410). Desta reflexão crítica, proposta por Adorno, destaco dois princípios: o de que a arte veicula e intensifica uma experiência "objetiva" e o de que ela é um acesso filosófico privilegiado e incontornável aos conflitos entre o novo e o arcaico. Os dois princípios dizem respeito ao papel estruturante da linguagem.

A descrição (o "assim é") e a ostensão (o "é isso") tornam-se distorcidas quando não repousam mais sobre uma tradição compartilhada, ao mesmo tempo em que a promessa da progressiva conquista de autonomia e liberdade frente à tradiçãao torna-se problemática. A arte traduz, desde Homero, a vivência desta cisão. E isso ajuda a ver que, no limite, a experiência que a arte veicula e intensifica não é uma experiência particular, do autor, embora dependa de sua singularidade ou do seu "gênio". No texto em questão, a experiência é pensada por Adorno como "continuidade da consciência em que perdura o ainda não existente e em que o exercício e a associação fundamentam uma tradição no indivíduo" (ADORNO, 1996, p. 405). Essa descrição da natureza processual da experiência estética, ou da experiência constitutiva da arte (o perdurar do ainda não existente) parece resvalar para um subjetivismo, para uma filosofia da consciência (a "continuidade da consciência" e "uma tradição 
no indivíduo") que Adorno entretanto rejeita. Se toda experiência é sempre também singular, isto é, exige a formação de um sujeito, nem por isso a literatura é mera expressão do sujeito e exercício de sua liberdade. Isto, o texto sobre Hölderlin conceitua de maneira exemplar:

Da mesma forma que o sujeito legislador, sua intenção, isto é, a primazia do sentido, cede à linguagem. A poesia de Hölderlin dela revela a dupla característica. Enquanto conceitual e predicativa, a linguagem se opóe à expressão subjetiva, e graças à sua generalidade reconduz aquilo que deve ser expresso ao dado e ao conhecido. É contra isto que se revoltam os poetas. Eles gostariam sem cessar de incorporar o sujeito e sua expressão à linguagem, até a sua morte. Não há dúvida que Hölderlin foi até certo ponto inspirado por isso, na medida em que ele resistiu à dimensão convencional da linguagem. Mas para ele isto se confunde com a antítese do ideal expressivo. Sua experiência dialética sabe não somente que a linguagem é superficial e repressiva, mas também que ela não conhece menos a verdade. A intenção subjetiva não poderia existir sem se perder na linguagem. O sujeito só existe como tal pela linguagem. (ADORNO, 1984, p. 337)

Dito isto, talvez o primeiro erro de toda a investida da literatura na formação escolar esteja em que esta, abandonada pela perda de uma legitimidade antes tấo autoevidente quanto questionável, não consegue superar o apego aos elementos arcaicos que a sustentavam: o embelezamento do já conhecido ou a mítica e misteriosa expressão do indivíduo. Mas, se isso procede, resta saber em que sentido a ênfase na linguagem e no conteúdo de verdade de uma obra de arte poderia servir de alternativa.

Esta alternativa pode parecer estar, de antemão, condenada ao fracasso. O caráter hermético da própria natureza poética da linguagem — como expresso num famoso verso de Hölderlin: "entendo a linguagem do éter, jamais a linguagem dos homens" - indica a complexidade do problema. Numa tirada irônica, Adorno diz que “...um jovem que [hoje] assim pensasse [isto é, como Hölderlin] seria objeto de chacotas ou seria entregue, sob alegação de autismo, 
a um benévolo tratamento psiquiátrico" (ADORNO, 1996, p. 398). Mas a tensão entre o espírito e a letra também poderia vir aqui em nosso socorro. $\mathrm{O}$ espírito, o conteúdo de verdade e o não-existente da obra de arte só se realizam através da matéria, da letra. $\mathrm{O}$ espírito não se confunde com a expressão e a intenção do autor, nem ainda com "o sentido" da obra. Ele é descrito como uma espécie de força ou processo que póe tudo em movimento e transfigura a própria materialidade da obra:

Espírito é isso, o que se manifesta, que não é mais elevado que a manifestação, mas tampouco é idêntico a ela, é o que em sua faticidade não tem caráter fático. Por ele, as obras de arte, coisas entre as coisas, tornam-se algo diferente do coisal e chegam a sê-lo precisamente pelo fato de serem coisas, não por sua localização espaço-temporal, senão por um processo imanente de coisificação que as converte no igual a si mesmo, no idêntico a si mesmo. Se não fosse assim, poderíamos apenas falar de espírito, do que simplesmente não tem caráter de coisa. Náo se trata apenas do spiritus, do alento, da alma das obras de arte enquanto fenômenos, senão também da força interna da obra, de sua força de objetivação... (ADORNO, 1986, p. 120)

Por tudo o que ela explicita, a tensão dialética entre o espírito e a letra talvez possa dar lugar a um conjunto de indicaçóes metodológicas importantes para que a ênfase na linguagem não se reduza à mera constatação da natureza hermética de toda expressão que procura escapar à estupidez babélica da cultura de massa, destinando alunos e outros incautos à sala do benévolo psiquiatra ou à mera condição de nefelibatas. Mais do que isso, ela certamente impede que resvalemos para concepçóes mistificadoras do literário ao recusar os lugares-comuns (mesmo aqueles eventualmente recobertos por elaboraçóes teóricas altamente refinadas). Dentre esses lugares comuns se destacam, além da centralidade da intenção do autor, do gênio, da expressão e conceitos correlatos, tanto a busca da unidade do sentido da obra (identificada com o new criticism e vertentes de interpretação simbólica) como toda tentativa de fazer da obra de arte um representante de filosofemas determinados a priori (cujo caso mais exemplar seria a "utilização abusiva" que Heidegger teria feito de 
Hölderlin, visando a sua "pseudo-concretização de palavras neo-ontológicas". Ver ADORNO, 1984, p. 324). De um ponto de vista “mais propositivo', destaca-se a oposição entre o novo e o arcaico.

Para Adorno, a obra de Hölderlin nos força a pensar sobre a questão das condiçóes para o aparecimento da verdade da poesia a partir dos embates entre a forma poética, o conteúdo - em que se destaca a perda da tradição - e a experiência entendida como "comportamento ascético diante do futuro" e "duração do não-existente". Ao contrário de leituras mais tradicionais, que José Paulo Paes, por exemplo, resume e subscreve, no prefácio às suas traduçóes dos poemas de Hölderlin (HÖLDERLIN, 1991), e que identificam neles um desejo de 'presença do divino no homem' como principal chave interpretativa, Adorno destaca o caráter irremediavelmente cindindo do universo desses poemas. Seria inviável entrar no mérito desta questão aqui. Mas cabe chamar a atenção para o fato de que esse confronto espelha um outro, paralelo, em que Adorno tematiza criticamente a idealização da origem e do mundo rural como estando mais próximos a uma autenticidade do Ser-aí heideggeriano.

A prática de Hölderlin dá conta do fato de que o sujeito, que se crê com ou sem razão imediato e último, é totalmente mediado. Essa modificação do gesto lingüístico, plena de consequências inumeráveis, deve entretanto ser compreendida como polêmica, e não ontológica: não é que a linguagem, reforçada pelo sacrifício da intenção subjetiva, esteja em si, por excelência, além do sujeito. Ao traçar os fios que a ligam ao sujeito, a linguagem fala no lugar do sujeito que não pode mais, ele mesmo, falar - Hólderlin foi sem dúvida o primeiro a suspeitar disso (ADORNO, 1984, p. 338).

As condiçôes históricas da linguagem impóem os parâmetros pelos quais podemos compreender a linguagem poética e o passado, e vice-versa. Daí que "a linguagem sem intenção de Hölderlin" e os deuses que a habitam sejam "um ideal":

A linguagem sem intençáo de Hölderlin, "a rocha nua da linguagem", é um ideal, aquele da linguagem revelada. A única 
relação que sua poesia tem com a teologia é ser um ideal, ela não a substitui. A distância que ela guarda com respeito a esta é aquilo que há nela de eminentemente moderno. Hölderlin, poeta do ideal, inaugura o processo que desemboca nos protocolos desprovidos de sentido de Beckett (ADORNO, 1984, p. 338).

A interdependência entre arte e filosofia revela aqui toda sua força. $\mathrm{O}$ conteúdo e a forma da idealização, "a rocha nua da linguagem”, não podem ser reconciliados com o que eles denunciam. Apenas uma filosofia que não imponha heteronomamente um sentido a priori ao poético pode transitar pela ambiguidade radical da poesia que mantém forte o elo com uma tradição muda, totalmente desprovida de sentido em meio à linguagem da tribo. E, se levamos a sério a ideia de que a arte é a derradeira linha de fuga em um mundo totalmente administrado, tampouco podemos nos conformar com uma relação de mão única. "A exigência que as obras de arte apresentam à filosofia é o que esta anteriormente pretendeu dar-lhes, mas que hoje, com sua tradicional roupagem, não é capaz de oferecer nem com respeito à consciência nem com respeito às obras de arte contemporâneas" (ADORNO, 1986, p. 343).

Por isso, somente a título de ilustração, parece importante indicar aqui em que sentido a filosofia, ao menos no caso de Adorno, parece responder à concretude do objeto sobre o qual se debruça. Alguns autores já chamaram a atenção para aspectos "pós-modernos" do pensamento de Adorno. Uma dialética que recusa, num só bloco, a síntese, a metafísica e qualquer aproximação a tudo que restou da crítica à metafísica (positivismo, fenomenologia, hermenêutica e mesmo, em certa medida, o marxismo) só pode ser um tipo de filosofia antinômica, mais próxima de perspectivas contemporâneas do que de Hegel. Mas foi Christoph Menke quem foi mais longe neste sentido, ao aproximar a estética negativa de Adorno e a filosofia de Derrida, o que nos ajuda a mostrar como a estética negativa trabalha o literário para além da mera denúncia da perda do sentido das obras de arte num mundo regido pela indústria cultural.

Como demonstra Menke, a estética negativa é formada por uma antinomia em que se opóem a autonomia da arte e sua soberania, isto é, o fato de que a arte não pode ser subsumida a nenhum âmbito não-estético e que ela 
pretende, ao mesmo tempo, dizer algo sobre e além do que a razão pode alcançar em domínios não-estéticos. A alternativa da resolução desconstrutiva desta antinomia estaria "na libertação do conceito de negatividade de Adorno de sua fusão com a negatividade da crítica social e em sua explicação como sendo a subversão do entendimento" (MENKE, 1999, p. xii). A soberania da arte se daria por esta subversão, e não pela crítica social da qual entretanto Adorno se recusaria a abrir mão. $\mathrm{O}$ ponto mais importante, porém, está na tese de que não é a arte ela mesma ou seu conteúdo que leva adiante esta subversão, e sim seus efeitos, consequências e repercussóes que são o fundamento da crítica. E aqui torna-se importante, portanto, indicar o aspecto fundamental desta crítica, que explica porquê a subversão da arte a pressupóe.

A interpretação literária de Adorno é regida pela forma ensaio, que trabalha sobre o regime da configuração (ADORNO, 2003, p. 31), dispositivo discursivo que contrapóe frases interpretativas incapazes de esgotar a obra, mas cria vazios capazes de superar o falso esgotamento da análise objetiva. Isto porque, como diz Adorno, "a pletora de significados encapsulada em cada fenômeno espiritual exige de seu receptor, para se desvelar, justamente aquela espontaneidade da fantasia subjetiva que é condenada em nome da disciplina objetiva” (ADORNO, 2003, pp. 17-18).

O ensaio deve permitir que a totalidade resplandeça em um traço parcial, escolhido ou encontrado, sem que a presença dessa totalidade tenha sido afirmada. Ele corrige o aspecto contingente e isolado de suas intuiçóes na medida em que estas se multiplicam, confirmam e delimitam, em seu próprio percurso ou no mosaico de suas relaçóes com outros ensaios... (ADORNO, 2003, p. 35)

Como observa Menke, “...a descontinuidade entre os enunciados do discurso interpretativo abre um espaço vazio que permite à experiência estética alojar-se a si mesma dentro desse discurso." (MENKE, 1999, p. 111). Graças a esse "método" aqui muito telegraficamente esboçado, a estética negativa de Adorno, certamente na esteira da filosofia de Benjamin, pôde ser precursora na atenção a temas e experiências estéticas absolutamente intangíveis para a maioria das demais tradiçôes filosóficas de início e meados do século XX, não 
apenas no que diz respeito ao sentido de ruptura das vanguardas artísticas e à releitura da arte ocidental num contexto de crise, mas também nos temas a eles relacionados: a indústria cultural, a ecologia, as mulheres, etc. Mas isso permanece insuficiente para evitar que a filosofia de Adorno seja quase sempre refém de uma visão pobre, esquemática e maniqueísta que a identifica com um discurso difícil e elitista que pretende salvar os produtos do espírito da maldição da indústria cultural, esquematismo que é preciso desconstruir para que a autocrítica da semiformação tenha hoje qualquer sentido. Seria preciso notar, por exemplo, que nos textos de interpretação literária de Adorno eclodem, malgrado a sombra daquela oposição esquemática, o substrato de experiências estéticas típicas da indústria cultural, que nos remete àquela natureza corpórea do espírito, a qual a filosofia ela mesma não pode ser subtraída, embora se esforce por permanecer no nível do conceito.

\section{Referências}

ADORNO, Theodor. "Anotações sobre Kafka”, in Prismas, crítica cultural e sociedade, São Paulo: Ática, 1998, tradução de Augustin Wernet e Jorge Mattos Brito de Almeida.

. "O ensaio como forma”, in Notas sobre literatura 1, São Paulo: Duas Cidades/34 Letras, 2003, tradução de Jorge de Almeida.

. "Teoria da Semicultura”, in Educação e Sociedade, ano VII, n56,

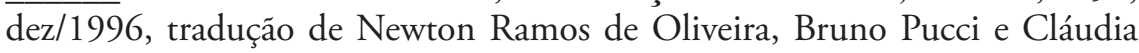
B.M. de Abreu.

. Terminología filosófica II, Madrid: Taurus, 1976, tradução de Ricardo S.O. de Urbina.

. Notes sur la littérature, Paris: Flammarion, 1984, trad. Sibylle Mulller.

Riaza.

. Teoria Estética, Madrid: Taurus, 1986, tradução de Fernando

HÖLDERLIN, Friedrich Poemas, São Paulo: Cia. das Letras, 1991. Tradução de José Paulo Paes.

MENKE, Christoph The sovereignity of art, aesthetic negativity in Adorno and Derrida, Massachusetts: MIT, 1999, traduzido por Neil Solomon. 


\title{
ADORNO ON LITERATURE AND EDUCATION
}

\author{
ABSTRACT \\ This paper presents correlated themes of Adorno's \\ theory of literature and Education. It draws attention \\ to 'postmodern aspects' of these themes and indicates its \\ importance to overcome the limits of a plaintive reading \\ of Adorno's ideas. \\ KEYWORDS: Adorno ; literature ; Post-Modernism. \\ Recebido em: 25/08/2014 \\ Aprovado em: 18/01/2015
}

